International Journal of Advancement in Life Sciences Research
Online ISSN: $2581-4877$
journal homepage http://ijalsr.org

Original Article

\title{
Trend of CD4 Cell Count at Initiation of Highly Active Antiretroviral Therapy (HAART) in Klinik Kesihatan Seremban (KKS)
}

\author{
Nur Zafirah*, K.Y. Gan, Payal Choudhury, A.B. Nabila Farhana, B. Shahnaz \\ Pharmacy Department, Seremban Health Clinic, Seremban Health District Office, Negeri Sembilan State Health \\ Department, Malaysia.
}

*NMRR ID : NMRR-17-2098-37774

${ }^{*}$ Correspondence E-mail: zaf pochahontas30@yahoo.com.my

\begin{abstract}
Background: CD4 T lymphocyte (CD4) is the most important marker that has been used in the management of HIV. The CD4 cell count provides information on the overall immune function of an HIV-infected patient. There is an overwhelming evidence that early initiation of HAART, at higher CD4 cell count will lead to virological and immunological success, prevent disease progression and reduces the social and economic costs of advanced HIV-related illness. We investigated the trend of CD4 cell count at initiation of HAART among HIV patients in KKS.

Materials and Method: All registered HIV patients from year 2012 to 2017 were enrolled in this study. Data was collected retrospectively from patient's data base and clinic's registry using a standardized data collection form. The data was analyzed by using SPSS version 16.0 and presented with percentages, mean and median values. We also compared the CD4 cell count at HAART initiation with recommendation in Malaysian Consensus Guideline on Antiretroviral. Additionally, we investigated the possible factors that lead to late initiation of HAART.

Results: Mean and median values of CD4 cell count at initiation of HAART were $411.03 \mathrm{cell} / \mathrm{mm}^{3}$ and $314 \mathrm{cell} / \mathrm{mm}^{3}$ respectively. There was an increasing trend of median CD4 cell count from 2014 until 2016 and in reducing trend in 2017. From 41 patients who were initiated on HAART, 68.3\% $(n=28)$ initiated HAART early while $31.7 \%(n=13)$ had late initiation. The late initiation of HAART was primarily due to late presenters.

Conclusion: CD4 cell count at initiation of HAART in KKS was found to be high. Generally the practice of initiating HAART in KKS is in compliance to the Malaysian Consensus Guideline in ART. However, a number of patients with late initiation of HAART is of concern. We recommend a strategic interventions to increase earlier detection of HIV patients and earlier start of HAART at higher CD4 cell count to prevent HIV transmission and improve mortality and morbidity.
\end{abstract}

Keywords : CD4, Antiretroviral, T lymphocyte, HIV

\section{Introduction}

CD4 T lymphocyte (CD4) is the most important marker that has been used in the management of HIV (Kumar et al.,2017). The CD4 cell count provides information on the overall immune function of an HIV-infected patient (Kumar et al., 2017). The measurement is critical in establishing thresholds for the initiation and discontinuation of antibiotics for opportunistic infection prophylaxis and in assessing the urgency to initiate highly active antiretroviral therapy (HAART) (Kumar et al.,2017)'There is an overwhelming evidence that early initiation 
of HAART, at higher CD4 cell count will lead to virological and immunological success, prevent disease progression and reduces the social and economic costs of advanced HIVrelated illness (Asfaw et al.,2015). Effective treatment averts death and also prevents transmission of HIV among serodiscordant couples (Asfaw et al.,2015). On the other hand, starting HAART at low CD4 cell counts results in acquired immunodeficiency syndrome (AIDS) defining disease for many patients (Yamashita et al.,2001). Studies also revealed that HIV patients who started HAART with a CD4 cell count $<200$ cells $/ \mathrm{mm}^{3}$ may not reach a normal CD4 cell count (Yamashita et al.,2001).

Initiation of HAART at higher CD4 cell counts has proven to have greater clinical benefits. Considering these clinical findings, experts from all over the world has updated their clinical guidelines regarding the recommended time point for initiating HAART. The European AIDS Clinical Society (EACS) recommends that patients whose CD4 cell counts are $<350$ cells $/ \mathrm{mm} 3$ to initiate HAART. However, the Department of Health and Human Services (DHHS) guidelines strongly recommend that HIV-positive patients with CD4 cell count $\leq 500$ cells/mm3 should initiate HAART (HHS). The World Health Organization (WHO) also recently updated their treatment guidelines to advise that HAART should be initiated for all HIV-positive adult patients, regardless of WHO clinical stage and CD4 cell count (WHO).

Malaysian Consensus Guideline on Antiretroviral Therapy have been revised consistent with WHO recommendation. In 2014, the guideline suggested the increasing of CD4 cell count threshold for ART initiation in asymptomatic HIV-positive patients from 200 cells $/ \mathrm{mm} 3$ to 350 cells $/ \mathrm{mm} 3$ (Consensus Guideline,2014). In 2017, the guideline have been updated where it recommends initiating therapy to all HIV patients regardless of CD4 count with priority for patients with advanced HIV clinical disease, individuals with CD4 count $\leq 350$ cells $/ \mathrm{mm} 3$, HIV-associated nephropathy (HIVAN), HIV/Hepatitis B virus co-infection, HIV/Hepatitis $C$ virus co infection and pregnant ladies (Consensus Guideline, 2016).
Eventhough there are many guideline that can be use as a reference, the initiation of HAART can be very challeging and subjective. Several studies have been done worlwide to see the trend of CD4 cell count at initiation of HAART. The Korea HIVAIDS cohort study reported that the median values of CD4 cell count at HAART initiation was 181 cells $/ \mathrm{mm} 3$ (Kiertiburanakul et al.,2014). Studies in 13 Asia country revealed that the overall median CD4 cell count at HAART initiation was 150cells/mm3 (Kiertiburanakul et al.,2014). Studies conducted in sub-Saharan Africa, South America and Asia reported the median CD4 count at start of therapy was 115 cells $/ \mathrm{mm}{ }^{[11]}$. All these studies concluded that CD4 cell count at HAART initiation was found to be very low (Kim et al., 2017) (Kiertiburanakul et al.,2014) (ART-LINC). In Malaysia respectively, there is lack of published study regarding the trend of CD4 cell count. Therefore, this study was designed to analyze the trend of CD4 cell count at initiation of HAART among HIV patients in Klinik Kesihatan Seremban and identify any possible factors that can lead to late initiation of HAART (HAART initiated at CD4 cell count $\leq 200$ cells $/ \mathrm{mm}^{3}$ ).

\section{Materials and Method}

This study was a retrospective study conducted in the pharmacy unit of Klinik Kesihatan Seremban (KKS). All registered HIV patients from year 2012 to 2017 were included in this study. Data was collected from patient's data base and clinic's registry using a standardized data collection form. Approval from the Malaysian Research Ethics Committee (MREC) and Clinical Research Centre through National Medical Research Register (NMRR) was obtained prior to the study. All information from the data collection was kept private and confidential. In this study, data on demographic status and CD4 cell count at diagnosis and HAART initiation were included. The data was analyzed by using SPSS version 16.0 and presented with percentages, mean and median values.

Additionally, we investigated the possible factors that lead to late initiation of HAART (Initiation of HAART at CD4 less than 200 
cell $/ \mathrm{ml}$ ). In this study, we also compared the CD4 cell count at HAART initiation with recommendation in Malaysian Consensus Guideline on Antiretroviral. This was to identify if HAART initiation in Klinik Kesihatan Seremban (KKS) comply to the National Guideline.

\section{Results}

1) Demographic data of HIV patients in KKS

As of December 2017, 64 patients were diagnosed with retroviral disease in KKS. All of these patients were included in this study. Based on Table 1, 87.5\% $(n=56)$ were male patients and $12.5 \% \quad(n=8)$ were female patients. Most patients belong to age group of $31-40(n=25,39.1 \%)$ followed by age group of 20-30 ( $n=22,34.4 \%)$, age group 41-50 $(n=8$, $12.5 \%)$ and age group 51-60 ( $n=7,10.9 \%)$. The least patients belong to age group of 61 $70(n=2,3.1 \%)$. As for ethnicity/race of patients, $60.9 \% \quad(n=39)$ were Malay, $20.3 \%$ $(n=13)$ were Indian, $14.0 \% \quad(n=9)$ were Chinese and the remaining $(4.7 \%, n=3)$ belong to other ethnicity. Malay patients make the greatest number. Patients were exposed to HIV via sexual and intravenous drug use
(IVDU). Most of them were heterosexual $(50 \%$, $\mathrm{n}=32)$, followed by homosexual $(37.5 \%, \mathrm{n}=24)$, bisexual $(1.6 \%, n=1)$. IVDU patients contribute about $10.9 \% \quad(n=7)$ of total population. Additionally, it showed that $9.3 \% \quad(n=6)$ of patients were co-infected with hepatitis $B$ and hepatitis $C$ whereas $3.1 \%(n=2)$ were coinfected with tuberculosis.

Table 1: Demographic data of HIV patients in KKS

\begin{tabular}{|c|c|}
\hline Particular & $\begin{array}{c}\text { Number of } \\
\text { patients (n=64) }\end{array}$ \\
\hline Gender & $56(87.5 \%)$ \\
Male & $8(12.5 \%)$ \\
Female & $22(34.4 \%)$ \\
\hline Age at diagnosis & $25(39.1 \%)$ \\
$31-40$ & $8(12.5 \%)$ \\
$41-50$ & $7(10.9 \%)$ \\
$51-60$ & $2(3.1 \%)$ \\
$61-70$ & \\
Route of transmission & $24(37.5 \%)$ \\
Sexual & $1(1.6 \%)$ \\
Homosexual & $32(50.0 \%)$ \\
Heterosexual & $7(10.9 \%)$ \\
IVDU & $2(3.1 \%)$ \\
TB & $6(9.3 \%)$ \\
Hepatitis B & $6(9.3 \%)$ \\
Hepatitis C & \\
\hline
\end{tabular}

\section{2) Trend of CD4 cell count at diagnosis}

Table 2: Trend of CD4 cell count at diagnosis

\begin{tabular}{lcccccc}
\hline Year & $\mathbf{2 0 1 2}$ & $\mathbf{2 0 1 3}$ & $\mathbf{2 0 1 4}$ & $\mathbf{2 0 1 5}$ & $\mathbf{2 0 1 6}$ & $\mathbf{2 0 1 7}$ \\
\hline Number of patients $(\mathbf{n = 6 4 )}$ & 2 & 5 & 2 & 3 & 25 & 27 \\
$\quad$ Mean value & 238.5 & 323.6 & 457.0 & 787.67 & 396.6 & 408.1 \\
$\quad$ Median value & 238.5 & 208.0 & 457.0 & 500.0 & 357.0 & 379.0 \\
\hline
\end{tabular}

Based on the study, 64 patients were suitable for analysis of CD4 cell count at time of diagnosis. The overall mean and median of CD4 cell count at time of diagnosis were $411.03 \mathrm{cell} / \mathrm{mm}^{3}$ and $379 \mathrm{cell} / \mathrm{mm}^{3}$ respectively. The median CD4 cell count was lowest in the year 2013 with $208 \mathrm{cell} / \mathrm{mm}^{3}$ and increased to $457 \mathrm{cell} / \mathrm{mm}^{3}$ in the year 2014. Highest median
CD4 cell count was reported in 2015 with 500 cell $/ \mathrm{mm}^{3}$. However, in 2016 the median CD4 decreased to $357 \mathrm{cell} / \mathrm{mm}^{3}$. This value increased in 2017 with $379 \mathrm{cell} / \mathrm{mm}^{3}$. 
Int J Adv Life Sci Res. Volume 1(2)1-7

\section{2) Trend of CD4 cell count at HAART initiation}

Table 3: Trend of CD4 cell count at HAART initiation

\begin{tabular}{ccccccc}
\hline Year & $\mathbf{2 0 1 2}$ & $\mathbf{2 0 1 3}$ & $\mathbf{2 0 1 4}$ & $\mathbf{2 0 1 5}$ & $\mathbf{2 0 1 6}$ & $\mathbf{2 0 1 7}$ \\
\hline Number of patients $(\mathbf{n = 4 1 )}$ & 2 & 4 & 2 & 2 & 9 & 22 \\
Mean value & 115.5 & 307.0 & 252.5 & 356.5 & 404.9 & 356.0 \\
Median value & 115.5 & 262.5 & 252.5 & 356.5 & 436.0 & 327.5 \\
\hline
\end{tabular}

From a total of 64 patients, only $64 \%(n=41)$ were on HAART and $36 \%(n=23)$ were not on HAART. The overall mean and median of CD4 cell count at initiation of HAART were 411.03 cell $/ \mathrm{mm}^{3}$ and $314 \mathrm{cell} / \mathrm{mm}^{3}$ respectively. The median CD4 cell count at HAART initiation was the lowest in 2012 with $115.5 \mathrm{cell} / \mathrm{mm}^{3}$.
However, the value increased in 2013 with $262.5 \mathrm{cell} / \mathrm{mm}^{3}$ and decreased in 2014 with $252.5 \mathrm{cell} / \mathrm{mm}^{3}$. There was an increasing trend of median CD4 cell count beyond 2014 with $356.5 \mathrm{cell} / \mathrm{mm}^{3}$ in 2015 and $436 \mathrm{cell} / \mathrm{mm}^{3}$ in 2016. However, this value decreased in 2017 with $327.7 \mathrm{cell} / \mathrm{mm}^{3}$.

Figure 1: Trend of CD4 cell count at HAART initiation

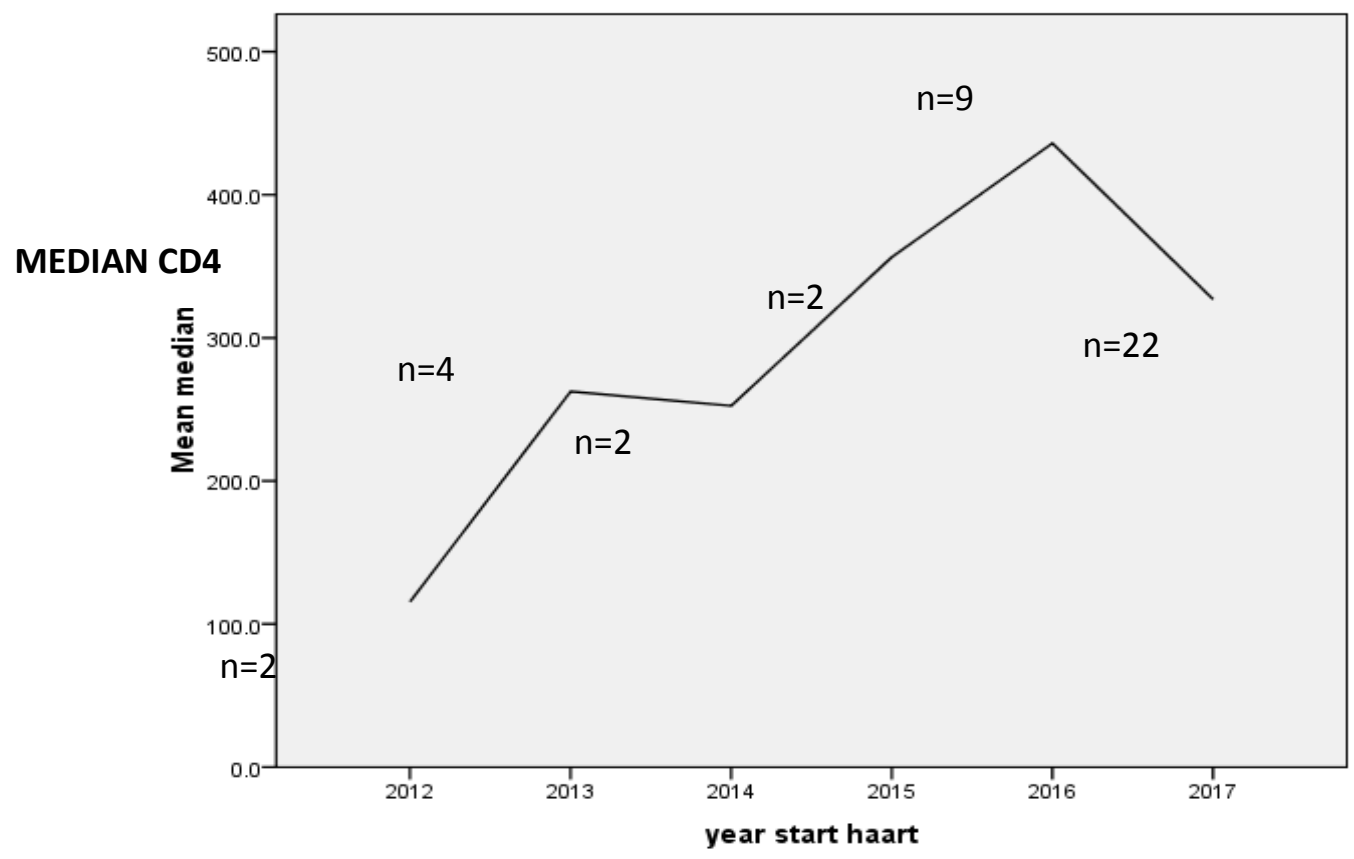

\section{3) Late initiation of HAART}

Table 4: Late Initiation of HAART

\begin{tabular}{lc}
\hline & Number of patient $(\mathbf{n}=\mathbf{4 1})$ \\
\hline Early initiation & $28(68.3 \%)$ \\
Late initiation & $13(31.7 \%)$ \\
\hline
\end{tabular}

In this study, late initiation of HAART was defined as initiation of HAART when CD4 cell count less than $200 \mathrm{cell} / \mathrm{mm}^{3}$. From 41 patients who were initiated on HAART, $68.3 \%$ $(n=28)$ initiated HAART early while $31.7 \%$ $(n=13)$ had late initiation of HAART (Table 4).
The late initiation of HAART was primarily due to late presenters. All patients with late initiation of HAART presented to HIV unit in KKS with low CD4 cell count (CD4 less than $200 \mathrm{cell} / \mathrm{mm}^{3}$ ). 
Table 5: Mean and median CD4 cell count in comparison with Malaysian Guideline on ART

\begin{tabular}{llcc}
\hline Year & $\begin{array}{l}\text { Recommended CD4 to start HAART } \\
\text { (Malaysian Consensus Guideline on ART) }\end{array}$ & $\begin{array}{c}\text { Mean CD4 } \\
\left(\text { cell/mm }{ }^{3}\right)\end{array}$ & $\begin{array}{c}\text { Median CD4 } \\
(\text { cell//mm }\end{array}$ \\
\hline $\mathbf{2 0 1 2}$ & Less than 200 cell/ml & 115.5 & 115.5 \\
$\mathbf{2 0 1 3}$ & Less than 200 cell/ml & 307.0 & 262.5 \\
$\mathbf{2 0 1 4}$ & Less than 350 cell/ml & 252.5 & 252.5 \\
$\mathbf{2 0 1 5}$ & Less than 350 cell/ml & 356.5 & 356.5 \\
$\mathbf{2 0 1 6}$ & Regardless of CD4 cell count & 404.9 & 436.0 \\
$\mathbf{2 0 1 7}$ & Regardless of CD4 cell count & 356.0 & 327.5 \\
\hline
\end{tabular}

\section{4) Comparison with Malaysian Consensus Guideline on antiretroviral therapy (ART)}

Based on Table 5, generally the initiation of HAART in KKS comply to Malaysian consensus Guideline except in 2013 and 2015. In 2013 and 2015, HAART has been initiated at higher CD4 counts compared to what is recommended. This serve no harm to the patient as starting HAART at higher CD4 cell will reduce the morbidity and mortality associated with HIV infection and prevent transmission.

\section{Discussion}

In this study, we observed that the overall median CD4 cell count at the time of diagnosis was $379 \mathrm{cell} / \mathrm{mm} 3$. This finding is higher when compared with other studies conducted in Asia, Korea, South America and Sub-Saharan Africa, which ranged from $67 \mathrm{cell} / \mathrm{mm} 3$ to 247 cell/mm3 (Kim et al.,2017)(Kiertiburanakul et al.,2014). The median CD4 cell count at diagnosis was lower than $350 \mathrm{cell} / \mathrm{mm} 3$ in 2012-2013 period and has increased to more than $350 \mathrm{cell} / \mathrm{mm} 3$ in 2014-2017 period. This finding is similar to previous study in other countries. In Korea HIV/AIDS cohort study, $76 \%$ of newly infected HIV patients from 2010 2012 were diagnosed at CD4+ cell count lower than 350 cells $/ \mathrm{mm} 3$ with overall median CD4+ cell count 195 cells $/ \mathrm{mm} 3$. However, in the three most recent years (2013-2015), the number of patients with CD4+ cell counts of more than 350 cells $/ \mathrm{mm} 3$ at the time of diagnosis has increased (Kim et al.,2017). In the United Kingdom, 49\% of newly infected HIV patients in 2011 were diagnosed at CD4+ cell count lower than 350 cells $/ \mathrm{mm}^{3}$ which was defined as late HIV diagnosis (V Delpech et al.,2013). Study in New York city showed that the median CD4 cell count at diagnosis increased from $325 \mathrm{cell} / \mathrm{mm} 3$ in 2006 to 379 cell/mm3 in 2015(Sarah et al.,2016).

Our study also showed that number of HIV patients receiving treatment from HIV Unit KKS has increased dramatically in 2016 and 2017. The finding of increasing median CD4 cell count at diagnosis and increasing number of HIV patient in primary healthcare facilities may be explained in part by several synergistic factors associated with improved primary healthcare access in Malaysia. To scale up access to HIV screening and treatment, HIV services has been decentralized to primary health facilities, closely linked with the main hospitals, along with the desire to make health care accessible, acceptable and affordable to the whole community. As of December 2015, about $90 \%$ (225) of Family Medicine Specialist country wide have been trained in HIV care and 50 mobile CD4 point of care test have been placed in primary care clinics. In 2015, HIV screening programme was available in 1 Malaysia Clinic (Global AIDS,2016).

The overall median CD4 cell count at initiation of HAART was $314 \mathrm{cell} / \mathrm{mm}^{3}$. Again, this finding was found to be higher when compared with Asia study with overall median CD4 of $150 \mathrm{cell} / \mathrm{mm}^{3}$. Similar to previous study in Asia, median CD4+ Cell count at HAART initiation in our study was low in 2012 and increased over time especially beyond 2014, which was the time Malaysian Consensus Guideline on ART have been revised the recommendation on CD4 cell count threshold for ART initiation. In 2014, the guideline suggested initiate ART in asymptomatic HIV-positive patient if CD4 cell count less than $350 \mathrm{cell} / \mathrm{mm}^{3}$ (Consensus Guideline,2016). In TAHOD-TASER Cohort Study, median CD4 cell count at the start of treatment was $115 \mathrm{cell} / \mathrm{mm}^{3}$ in 2008 and has increased substantially to $302 \mathrm{cell} / \mathrm{mm} 3$ after 2011 (Kiertiburanakul et al.,2014). This CD4+ 
cell count trend was similar to the findings from a study performed in Shanghai, China. The median CD4+ cell count had increased from 65 cells $/ \mathrm{mm}^{3}$ in 2006 to 203 cells $/ \mathrm{mm}^{3}$ in 2011(Shen et al.,2011).

At the same time, we found that the overall number of patients who started HAART in KKS increased sharply on 2016 and 2017. In 2012, only 2 patients had been receiving HAART in KKS. However, this value increases in 2016 and 2017 with 9 patients and 22 patients respectively. Generally, based on the finding presented in Table 5, the practise of initiating HAART in KKS was comply to Malaysian Consensus Guideline on ART version 2012,2014 and 2016. But there was still 36\% of total HIV patients in KKS not on HAART. This issue need to be address by healthcare provider in KKS in order to achieve the aim of National Strategic Plan Ending AIDS (NSPEA) Malaysia. NSPEA Malaysia 2016-2030 aims to reach the $90-90-90$ target with $90 \%$ of key populations tested for HIV and knowing their results, $90 \%$ of people infected with HIV placed on ART and $90 \%$ of these patients adhering to treatment with suppressed viral load (Global AIDS,2016).

Recently published results of the START randomized controlled trial provide the first evidence of the clinical benefits of early ART initiation after HIV diagnosis, including major reductions in serious AIDS-related events, serious non-AIDS-related events, and death [17]. Of $41(64 \%$ of total) patients who were initiated on HAART from 2012-2017 in KKS, $13(31.7 \%)$ were late initiator, primarily due to late presenter. It showed that these patients were presented in KKS with low CD4 count (CD4 less than $200 \mathrm{cell} / \mathrm{mm}^{3}$ ). This finding is consistent with Korea study where it was reported that the increased in late initiation of HAART in recent years is primarily due to an increasing proportion of late presenters. In this study, the number of late initiator was lower with $31.7 \%$ in comparison with MASTER Cohort with 54\% (Elena et al.,2016). Several factors were found to be associated with late presentation such as male gender, older age, migration, injecting drug users (IDU), and heterosexual HIV exposure (Elena et al.,2016) (Su Jin et al.,2016). In spite of the availability and accessibility of HIV testing opportunities and efforts, some people are being late to test in the course of HIV infection. Late presentation into care and consequent delays in ART initiation are associated with more HIVrelated, opportunistic infections, increased morbidity and mortality, diminished responses to ART, and health care expenditures ( $\mathrm{Su}$ Jin et al.,2016). In order to achieve earlier entry into care, efforts to reduce the patients who first seek HIV care at the late stage are needed.

Our study has limitations. The low number of patients recruited for this study caused an obvious limitation in the interpretation of findings of this study and its power. Additional survey in multiple zones ofthe state or country with larger populations will help to endorse these results. This study also does not compare the CD4 cell count at diagnosis with baseline characteristic data susch as gender,race, transmission route and coinfection. However, we strongly believed that the data of this study provides a basic understanding of immune status of HIV patients in KKS at diagnosis and initiation of HAART.

\section{Conclusion}

In conclusion, the median CD4 cell count at diagnosis and HAART initiation in KKS was found to be high. However, the reducing trend of CD4 cell count at HAART initiation from 2016 to 2017 is of concern. Although more than half of total HIV patients in KKS were on treatment, there was a significant number of patients were still late to receive HAART. Earlier HAART initiation at higher CD4 cell count remains a challenge. We recommend a strategic interventions to increase earlier detection of HIV patients and earlier start of HAART at higher CD4 cell count to prevent HIV transmission and improve mortality and morbidity. 


\section{References}

Asfaw, A., Ali, D., Eticha, T., Alemayehu, A., Alemayehu, M., Kindeya, F. (2015). CD4 cell count trends after commencement of antiretroviral therapy among HIV-infected patients in Tigray, Northern Ethiopia: a retrospective cross-sectional study. PLOS One. 10:e0122583.

Braunstein, S. L., Robertson, M. M., Myers, J., Abraham, B., Nash, D. (2016). Increase in $\mathrm{CD}^{+}{ }^{+} \mathrm{T}$-Cell Count at the Time of HIV diagnosis and antiretroviral treatment initiation among persons with HIV in New York city. The Journal of Infectious Diseases, 214:(11). 1682-1686.

Delpech, V., Brown, A. E., Croxford, S., Chau, C., Polavarapu, V., Cooper, N., Rooney, G. Yin, Z. (2013). Quality of HIV care in the United Kingdom: key indicators for the first 12 months from HIV diagnosis. HIV Medicine, 14 (Suppl. 3), 19-24.

Department of Health and Human Services (HHS).(2018). Panel on Antiretroviral Guidelines for Adults and Adolescents. Guidelines for the use of antiretroviral agents in HIV-1-infected adults and adolescents. https://aidsinfo.nih.gov/guidelines.

European AIDS Clinical Society. (EACS).(2017). Guidelines for the Clinical. Management and Treatment of HIV Infected Adults in Europe. EACS Guidelines 9.0. 10-14.

Global AIDS Response Progress Report 2016.

Insight Start Study Group, Lundgren, J. D., Babiker, A. G. et. al. (2015). Initiation of antiretroviral therapy in early asymptomatic HIV infection. N Engl J Med. 373. 795-807.

Jeong, S. J., Italiano, C., Chaiwarith, R., Ng, O. T., Vanar, S., Jiamsakul, A., ... Choi, J. Y. (2016). Late Presentation into Care of HIV Disease and Its Associated Factors in Asia: Results of TAHOD. AIDS Research and Human Retroviruses, 32(3), 255-261. http://doi.org/10.1089/aid.2015.0058

Kiertiburanakul, S., Boettiger, D., Lee, M. P., Omar, S. F., Tanuma, J., Ng, O. T., ... Sungkanuparph, S. (2014). Trends of CD4 cell count levels at the initiation of antiretroviral therapy over time and factors associated with late initiation of antiretroviral therapy among Asian HIV-positive patients. Journal of the International AIDS Society, 17(1), 18804. http://doi.org/10.7448/IAS.17.1.18804

Kim MJ, et al. (2017). Trend of CD4+ Cell Counts at Diagnosis and Initiation of Highly Active Antiretroviral Therapy (HAART): Korea HIV/AIDS Cohort Study, 1992-2015. Infect Chemother, 49(2).101-108.

Koh Kwee Choy (2017). Malaysian Consensus Guidelines on Antiretroviral Therapy 2017 Ministry of Health Malaysia.

Kumar, M., Kumar, R., Mahdi, A. A., Dhole, T. N. (2017). Study of Viral Load and CD4 Count in Diagnosis of HIV-1 Positive Patients. J Fam Med. 4(4). 1117.

Raffetti, Elena et al. (2016). The risk of late or advanced presentation of HIV infected patients is still high, associated factors evolve but impact on overall mortality is vanishing over calendar years: results from the Italian MASTER Cohort. BMC Public Health. 16. 878.

Shen, Y., Wang, J., Qi, T., Wang, Z., Lu, H. (2013) Trends in clinical characteristics of HIVinfected patients initiating antiretroviral therapy in Shanghai from 2006 to 2011. Int J STD AIDS, 25. 504-10.

WHO (2015). Guideline on When to Start Antiretroviral Therapy and on Pre-Exposure Prophylaxis for HIV. World Health Organization, Geneva. Available from: https://www.ncbi.nlm.nih.gov/books/NBK32711 5/

Yamashita, T. E., Phair, J. P., Muñoz, A., Margolick, J. B., Detels, R., O'Brien, S. J., Mellors, J. W., Wolinsky, S. M., Jacobson, L. P. (2001) Immunologic and virologic response to highly active antiretroviral therapy in the Multicenter AIDS Cohort Study. AIDS. 15, 73546. 